\title{
First-tier detection of intragenomic 16S rRNA gene variation in culturable endophytic bacteria from cacao seeds
}

\author{
Cleiziane B da Silva ${ }^{1}$, Hellen R M dos Santos ${ }^{1}$, Phellippe A S Marbach ${ }^{2}$, Jorge T de Souza ${ }^{3}$, Valter Cruz-Magalhães \\ 1,3 , Ronaldo C Argôlo-Filho ${ }^{\text {Corresp., } 1}$, Leandro L Loguercio ${ }^{\text {Corresp. } 1}$ \\ ${ }^{1}$ Dept. of Biological Sciences (DCB), State University of Santa Cruz (UESC), Ilhéus-BA, Brazil \\ 2 Center for Agricultural, Biological and Environmental Sciences (CCAAB), Federal University of Recôncavo da Bahia (UFRB), Cruz das Almas-BA, Brazil \\ 3 Dept. of Plant Pathology, Federal University of Lavras (UFLA), Lavras-MG, Brazil
}

Corresponding Authors: Ronaldo C Argôlo-Filho, Leandro L Loguercio

Email address: rcargolofilho@uesc.br, leandro@uesc.br

Background. Intragenomic variability in 16S rDNA is a limiting factor for taxonomic and diversity characterization of Bacteria, and studies on its occurrence in natural/environmental populations are scarce. In this work, direct DNA amplicon sequencing coupled with frequent-cutter restriction analysis allowed detection of intragenomic $16 \mathrm{~S}$ rDNA variation in culturable endophytic bacteria from cacao seeds in a fast and attractive manner.

Methods. Total genomic DNA from 65 bacterial strains was extracted and the 16S rDNA hyper variable V5-V9 regions were amplified for enzyme digestion and direct Sanger-type sequencing. The resulting electropherograms were visually inspected and compared to the corresponding Alul-restriction profiles, as well as to complete genome sequences in databases. Restriction analysis were employed to substitute the need of amplicon cloning and re-sequencing. A specifically improved polyacrylamide-gradient electrophoresis allowed to resolve 5-bp differences in restriction fragment sizes. Chi-square analysis on 2 $\times 2$ contingency table tested for the independence between the 'number of Alul bands' and 'type of eletropherogram'.

Results. Two types of electropherograms were obtained: unique template, with single peaks per base (clean chromatograms), and heterogeneous template, with various levels of multiple peaks per base (mixed chromatograms). Statistics revealed significant interaction between number of restriction fragments and type of electropherogram for the same amplicons: clean or mixed ones associated to $\leq 5$ or $\geq 6$ bands, respectively. The mixed-template pattern combined with the Alul-restriction profiles indicated a high proportion of $49 \%$ of the culturable endophytes from a tropical environment showing evidence of intragenomic 16S rDNA heterogeneity.

Conclusion. The approach presented here was useful for a rapid, first-tier detection of intragenomic variation in culturable isolates, which can be applied in studies of other natural populations; a preliminary view of intragenomic heterogeneity levels can complement culture-dependent and -independent methods. Consequences of these findings in taxonomic and diversity studies in complex bacterial communities are discussed. 


\section{First-tier detection of intragenomic 16S rRNA gene}

2 variation in culturable endophytic bacteria from cacao

3 seeds

4

5

6 Cleiziane Bispo da Silva ${ }^{1}$, Hellen Ribeiro Martins dos Santos ${ }^{1}$, Phellippe Arthur Santos

7 Marbach $^{2}$, Jorge Teodoro de Souza ${ }^{3}$, Valter Cruz-Magalhães ${ }^{1,3}$, Ronaldo Costa Argôlo-Filho',

8 Leandro Lopes Loguercio ${ }^{1}$

${ }^{1}$ Dept. of Biological Sciences (DCB), State University of Santa Cruz (UESC), Ilhéus-BA,

12 Brazil.

$13{ }^{2}$ Center for Agricultural, Biological and Environmental Sciences (CCAAB), Federal University

14 of Recôncavo da Bahia (UFRB), Cruz das Almas-BA, Brazil.

$15{ }^{3}$ Dept. of Plant Pathology, Federal University of Lavras (UFLA), Lavras-MG, Brazil.

Corresponding Authors:

19

Leandro Lopes Loguercio ${ }^{1}$

Ronaldo Costa Argôlo-Filho ${ }^{1}$

${ }^{1}$ Post-graduation Program in Genetics and Molecular Biology (PPG-GBM), Dept. Biological 24 Sciences (DCB), State University of Santa Cruz (UESC), Pav. Jorge Amado, Rod. BR 415, Km 25 16, Salobrinho, Ilhéus-BA, 45662-000, BRAZIL 26

Email address: leandro@uesc.br / rcargolofilho@uesc.br 
28

29

30

31

32

33

34

35

36

37

38

39

40

41

42

43

44

45

46

47

48

49

50

51

52

53

54

55

56

57

58

59

60

61

62

63

64

65

66

67

\section{Abstract}

Background. Intragenomic variability in $16 \mathrm{~S}$ rDNA is a limiting factor for taxonomic and diversity characterization of Bacteria, and studies on its occurrence in natural/environmental populations are scarce. In this work, direct DNA amplicon sequencing coupled with frequentcutter restriction analysis allowed detection of intragenomic 16S rDNA variation in culturable endophytic bacteria from cacao seeds in a fast and attractive manner.

Methods. Total genomic DNA from 65 bacterial strains was extracted and the 16S rDNA hyper variable V5-V9 regions were amplified for enzyme digestion and direct Sanger-type sequencing. The resulting electropherograms were visually inspected and compared to the corresponding AluI-restriction profiles, as well as to complete genome sequences in databases. Restriction analysis were employed to substitute the need of amplicon cloning and re-sequencing. A specifically improved polyacrylamide-gradient electrophoresis allowed to resolve 5-bp differences in restriction fragment sizes. Chi-square analysis on 2 x 2 contingency table tested for the independence between the 'number of AluI bands' and 'type of eletropherogram'.

Results. Two types of electropherograms were obtained: unique template, with single peaks per base (clean chromatograms), and heterogeneous template, with various levels of multiple peaks per base (mixed chromatograms). Statistics revealed significant interaction between number of restriction fragments and type of electropherogram for the same amplicons: clean or mixed ones associated to $\leq 5$ or $\geq 6$ bands, respectively. The mixed-template pattern combined with the AluIrestriction profiles indicated a high proportion of $49 \%$ of the culturable endophytes from a tropical environment showing evidence of intragenomic 16S rDNA heterogeneity.

Conclusion. The approach presented here was useful for a rapid, first-tier detection of intragenomic variation in culturable isolates, which can be applied in studies of other natural populations; a preliminary view of intragenomic heterogeneity levels can complement culturedependent and -independent methods. Consequences of these findings in taxonomic and diversity studies in complex bacterial communities are discussed.

\section{Introduction}

Correct taxonomic identification and proper estimates of bacterial diversity are very important issues, due to wide environmental distribution, ecological functions, pathogenic potential and biotechnological applications of this domain. For more than a century, the identification/classification of bacteria has been done exclusively through culture-dependent methods, based on a series of morphological, physiological and biochemical tests after growth in appropriate media (Janda and Abbott, 2002). With the advances in molecular genetics, a criterion of DNA-DNA hybridization (DDH) showing a reassociation of $70 \%$ or more was established to define genospecies (Stackebrandt and Goebel, 1994). In the genomic era, various concepts and 
68

69

70

71

72

73

74

75

76

77

78

79

80

81

82

83

84

85

86

87

88

89

90

91

92

93

94

95

96

97

98

99

100

101

102

103

104

105

106

107

approaches have been debated as biologically meaningful systems for bacterial species definition (Konstantinidis et al., 2006).

Sequencing of the $16 \mathrm{~S}$ ribosomal RNA gene in prokaryotes has been widely used to determine taxonomic and phylogenetic relationships (Clarridge, 2004; Armougom and Raoult, 2009; Manaka et al., 2017). Bacterial strains with $\geq 70 \%$ DNA-DNA reassociation usually have $>97 \%$ identity in their 16S rRNA gene sequence; on the other hand, less than $70 \%$ DNA-DNA hybridization, even with almost identical 16S rDNAs, may indicate different species (Janda and Abbott, 2007). This is especially relevant when ecological niches are included in the comparative analyses (Gevers et al., 2005; Konstantinidis et al., 2006). Multi-locus sequencing analysis (MLSA) is also used for prokaryotic species definition, counting on a set of specific genes with sufficient evolutionary signals to allow fine discrimination between genetically close strains (Gevers et al., 2005). Polyphasic approaches including all these methods have been regarded as the most suitable manner for taxonomic characterization of bacteria (Das et al., 2014; Sarethy et al., 2014).

An often overlooked aspect to consider in the analyses of newly isolated strains from environmental samples (including endophytes) is how they are preliminarily assigned to a taxon. Studies have shown that horizontal gene transfer and recombination within the 16S rDNA do occur in bacteria (Schouls et al., 2003; Zhaxybayeva et al., 2006; Kitahara and Miyazaki, 2013; Tian et al., 2015). Experimental transfer of complete rRNA operons within and between species have resulted in viable organisms with heterologous 16S rRNA genes from two other species (Asai et al., 1999). Since some strains can carry up to 15 copies of the 16S rRNA gene (Klappenbach et al., 2001; López-López et al., 2007; Engene and Gerwick, 2011; Sun et al., 2013), transfer and recombination of segments can lead to a mosaic-like structure, i.e. different sequences of the 16S rDNA within the same cell (Eardly et al., 1996; Schouls et al., 2003; Tian et al., 2015). The presence of multiple 16S rDNA copies and possible intragenomic heterogeneity can be, therefore, a limiting factor for both correct identification and counting of operational taxonomic units (OTUs) in biodiversity studies of both culturable and unculturable bacteria (Coenye and Vandamme, 2003; Pei et al., 2010; Chen et al., 2015). Although culturable microbes represent only $0.1-5 \%$ of the estimated total microbial diversity of any given environment (Bull, 2004), the levels of $16 \mathrm{~S} \mathrm{rDNA}$ intragenomic variation in a culturable population may provide a glance of what can occur in the whole community. Knowing such variation is useful in studies on microbial ecology and diversity, to prevent overestimation of this latter parameter (Sun et al., 2013) and to provide correction factors to compensate it.

Due to an intimate interaction with the plants, endophytic microbial symbionts can play important roles in host adaptation and evolution (e.g. Bulgarelli et al., 2013; Turner et al., 2013; Agler et al., 2016), performing relevant biological functions, such as increased photosynthetic efficiency, growth promotion, tolerance to abiotic and resistance to biotic stresses, including antagonism towards phytopathogens (Barrow et al., 2008; Hanada et al., 2009; Andreotte et al., 2014; Hardoim et al., 2015; Berg et al., 2017). Endophytes also represent a potential source of bioactive compounds with a variety of applications in agriculture and industry (Schulz et al., 
108

109

110

111

112

113

114

115

116

117

118

119

120

121

122

123

124

125

126

127

128

129

130

131

132

133

134

135

136

137

138

139

140

141

142

143

144

145

146

147

2002; Schulz and Boyle, 2005; Leite et al., 2013; Gouda et al., 2016). The great genetic, molecular and biochemical diversification in microorganisms is the basis of these processes, with their greatest biodiversity being long acknowledged in tropical latitudes (Strobel and Daisy, 2003; Arnold and Lutzoni, 2007; Duarte et al., 2013). The cacao tree is an interesting experimental model for these regions, due to a globally recognized importance for its economic, social, and environmental characteristics (Donald, 2004; Schroth et al., 2011; Beg et al., 2017; Wickramasuriya and Dunwell, 2018). Moreover, exploratory studies on tropical cacao communities of endophytic fungi and bacteria in different plant tissues have been conducted, with emphasis on improvement of the plant productivity based on biological control and growth promotion (Rubini et al., 2005; Crozier et al., 2006; Mejía et al., 2008; Hanada et al., 2009; 2010; Melnick et al., 2011; Leite et al., 2013; Tchinda et al., 2016).

Mixed electropherograms obtained from Sanger sequencing can be an interesting first-tier approach to assess polymicrobial samples composition or intragenomic heterogeneity of rRNA genes/operons. Previous studies have demonstrated the feasibility of employing direct sequencing of PCR-amplified 16S rDNA stretches to detect the presence of multiple microbes (Kommedal et al., 2008; Hartmeier and Justesen, 2010) or intragenomic rDNA variability in clinical samples of culturable isolates (Chen et al., 2015) by visually inspecting the corresponding mixed chromatograms. In the present work, a similar approach of Sanger-type chromatogram-based assessment, but complemented with frequent-cutter (AluI) restriction analyses was applied to study intragenomic variability in $16 \mathrm{~S}$ rDNA in a set of culturable endophytic bacteria from cacao seeds. The results confirmed detection of intragenomic variation in individual isolates, suggesting this feature as being present in natural/environmental populations at high frequencies.

\section{Materials \& Methods}

\section{Bacterial strains collection}

The 65 endophytic bacterial isolates used in this work belonged to the Laboratory of Agroindustry Applied Microbiology of the State University of Santa Cruz (LABMA/UESC, Ilhéus-BA, Brazil), and were previously obtained from pulp adhered to seeds from cacao pods (da Silva, 2013). The isolates were purified by the single-colony streak-plate method in Nutrient Agar and Tryptone Soy Agar, and maintained at $30^{\circ} \mathrm{C}$ in the dark. This single-colony streaking and culturing procedure was repeated at least three times to assure that only homogeneous/pure colonies were obtained. The total DNA from the isolates was extracted by the Doyle and Doyle (1987) method.

\section{Amplification and sequencing of the $16 \mathrm{~S}$ rRNA genes from culturable isolates}

Amplification of the V5-V9 hypervariable region of the 16S rRNA gene from the bacteria was performed by PCR with the primer-pair 799F (5'-AACMGGATTAGATACCCKG-3') and 
148 U1492R (5'-GGTTACCTTGTTACGACTT-3') (Chelius and Triplett, 2001). Each 25- $\mu \mathrm{L}$ (final 149 volume) of polymerase chain reaction contained $8 \mathrm{ng}$ of extracted DNA template, $2.5 \mu \mathrm{L}$ of 10x 150 Taq buffer, $1.25 \mu \mathrm{L}$ of $50 \mathrm{mM} \mathrm{MgCl}_{2}, 2.5 \mu \mathrm{L}$ of $2 \mathrm{mM}$ dNTP, $0.2 \mu \mathrm{L}$ of Platinum ${ }^{\circledR}$ Taq DNA 151 polymerase $\left(5 \mathrm{U}^{-1}\right.$ ) (Invitrogen $\left.{ }^{\mathrm{TM}}\right), 15$ pmoles of $799 \mathrm{~F}, 7.5$ pmoles of $\mathrm{U} 1492 \mathrm{R}$, and $0.25 \mu \mathrm{L}$ $152 \mathrm{BSA}$ at $0.1 \%$. The reaction was performed under the following conditions: 3 min at $96^{\circ} \mathrm{C}$, 153 followed by 30 cycles of $20 \mathrm{~s}$ at $94^{\circ} \mathrm{C}, 40 \mathrm{~s}$ at $58^{\circ} \mathrm{C}$ and $40 \mathrm{~s}$ at $72^{\circ} \mathrm{C}$, with a final extension step 154 at $72^{\circ} \mathrm{C}$ for $10 \mathrm{~min}$. Aliquots of $5 \mu \mathrm{L}$ of each reaction were analyzed on $1 \%(\mathrm{w} / \mathrm{v})$ agarose gel 155 electrophoresis in TBE buffer.

156 The amplified fragments were purified from agarose gels using PureLink ${ }^{\circledR}$ Quick Gel 157 Extraction Kit (Invitrogen ${ }^{\mathrm{TM}}$ ), following manufacturer's recommendations. The purified DNA

158

159

160

161

162

163

164

165

166

167

168

169

170

171

172

173

174

175

176

177

178

179

180

181

182

183

184

185

186

187 from gel were quantified by the NanoDrop ND-1000 spectrophotomer (Thermo Scientific ${ }^{\mathrm{TM}}$ ) prior to sequencing. The gel-purified amplicons were sequenced through the ABI-PRISM ${ }^{\circledR} 3100$ Genetic Analyzer System, equipped with 50-cm capillaries and POP6 polymer. For each sequencing reaction, $3 \mu \mathrm{L}$ of the BigDye ${ }^{\mathrm{TM}}$ Terminator v3.1 Cycle Sequencing RR-100 reagent was used, with DNA template at $\sim 50 \mathrm{ng}$, and 2.5 pmoles of the $799 \mathrm{~F}$ primer, in a final volume of $10 \mu \mathrm{L}$. The sequencing reactions were done in GeneAmp ${ }^{\circledR}$ PCR System 9700 thermocycler under the following conditions: $3 \mathrm{~min}$ at $96^{\circ} \mathrm{C}$, followed by 25 cycles of $10 \mathrm{~s}$ at $96^{\circ} \mathrm{C}, 5 \mathrm{~s}$ at $55^{\circ} \mathrm{C}$ and 4 $\min$ at $60^{\circ} \mathrm{C}$. The reaction products were precipitated with $4 \mathrm{x}$ their volume with $75 \%$ isopropanol for $30 \mathrm{~min}$, centrifuged at $13 \mathrm{krpm}$ for $15 \mathrm{~min}$; the pellet was washed with $60 \%$ ethanol and dried to completion. Subsequently, the pellets were diluted in $10 \mu \mathrm{L}$ of Hi-Di formamide, denatured at $95^{\circ} \mathrm{C}$ for $5 \mathrm{~min}$ and cooled on ice also for $5 \mathrm{~min}$, prior to being electro-injected in the automatic sequencer. The sequencing data were collected by the Data Collection v 1.0.1 program with the following parameters: Dye Set 'Z', Mobility File 'DT3100POP6 \{BDv3\} v1.mob', Run Module 1'StdSeq50_POP6_50cm_cfv_100', and analysis Module 1 'BC 3100SR_Seq_FASTA.saz'.

\section{Electropherograms and restriction analyses of the $16 \mathrm{~S} r \mathrm{RNA}$ gene sequences}

A visual inspection of the resulting electropherograms was carried out, including analysis of peaks definition and intensity, the presence of overlapping peaks and extension of the overlapping stretches. For a preliminary identification of isolates, the final base-called, processed sequences (through the ABI Sequencing Analysis application) obtained from the 16S rRNA genes of the endophytic bacterial isolates were submitted to the GenBank by the BlastN software (http://www.ncbi.nlm.nih.gov/BLAST/). Based on the list of genera/species obtained from the BlastN, a further search was done for those with complete genomes deposited in the database. For quality and safety of information from the BlastN search, only those sequences obtained from clean, single-peaks chromatograms of the bacterial endophytic isolates from cacao (see above) were aligned with the complete genome sequences of the corresponding species (see Results). A supplementary multi-fasta text file containing these sequences is provided, with the isolates ordered according to levels of identity retrieved from BlastN (Table 1). In addition, all the corresponding electropherograms, labelled with the corresponding isolate identification, were provided as a compressed file (*.zip) as supplemental material. 
188

189

190

191

192

193

194

195

196

197

198

199

200

201

202

203

204

205

206

207

208

209

210

211

\section{Statistics}

213 A non-parametric chi-square analysis was performed in a 2 x 2 contingency table, with 214

215

216

217

218

219

220

221

222

223

224

225

226

227

The same PCR products subjected to sequencing were also digested with AluI (AG/CT) restriction enzyme (Uniscience ${ }^{\circledR}$ do Brasil) in reactions composed of $0.8 \mu \mathrm{L}$ of $10 \mathrm{x}$ enzyme buffer, $0.25 \mu \mathrm{L}$ of the AluI enzyme $\left(10 \mathrm{U} \mu \mathrm{L}^{-1}\right), 2 \mu \mathrm{L}$ of the PCR reaction, brought up to final volume of $8 \mu \mathrm{L}$ with ultra-pure water. The AluI-digestion reactions were incubated in a water bath at $37^{\circ} \mathrm{C}$ for $50 \mathrm{~min}$, following the enzyme manufacturer's recommendations. This 4-bp frequent cutter was chosen because it yielded sufficiently discriminatory restriction profiles after electrophoresis for the amplified V5-V9 16S rRNA gene regions from the bacterial isolates (dos Santos, 2017).

For the separation of the AluI digestion products, a previously defined procedure with a high-resolution ability (dos Santos, 2017) was used for the analysis. The AluI digestions were submitted to vertical electrophoresis in $5-11 \%$ polyacrylamide $(\mathrm{w} / \mathrm{v})$ gradient gel in $1 \mathrm{x}$ TAE buffer (20 mM Tris-acetate, $0.5 \mathrm{mM}$ EDTA, $\mathrm{pH} 8$ ) at $80 \mathrm{~V}$ for $16 \mathrm{~h}$. Afterwards, the gels were stained for $30 \mathrm{~min}$ in the dark, using a solution composed of $15 \mu \mathrm{L}$ of GelGreen ${ }^{\mathrm{TM}}$ for each 50 $\mathrm{mL}$ of distilled water $\left(3: 10^{4}\right.$ ratio). After the staining time, the gels were photodocumented in Blue LED Transilluminator (Nippon Genetics Europe). The gel images were analyzed for counting of the restriction fragments generated; this procedure allowed the unambiguous detection of individual fragments with a size-difference equal to, or greater than $5 \mathrm{bp}$. Additionally, in silico analyses of the endophytic bacterial sequences with clean, single-peaks chromatograms was performed to locate $A l u I$ cleavage sites and predict the number of fragments to be generated after the restriction digestions.

Each isolate's $16 \mathrm{~S}$ rDNA was subjected at least twice to the whole procedure of PCR amplification, sequencing and enzyme digestion, thereby composing a minimum of two biological replicates per sequence obtained; the results were consistent among replicates. correction of Yates, to test the null hypothesis of independence between the variation factors, i.e. "type of chromatogram" ('clean' and 'mixed') vs "number of AluI fragments" ('up to 5 bands' and ' 6 or more bands'). These two categories of AluI-generated fragments were set according to the average number of restriction sites per single $16 \mathrm{~S}$ rDNA sequences. After assessing $14316 \mathrm{~S}$ rDNA sequences of endophytic bacteria from databases, we found that $82 \%$ of them have 2 to 4 AluI sites in the V5-V9 region, which generates 3 to 5 restriction fragments. Therefore, if the PCR amplicons are composed of more than a single type of template, then the number of AluIbands generated after digestion have $\sim 82 \%$ probability to be equal or higher than six. A very significant chi-square value $(P<0.01)$ indicates association between the type of chromatogram and the number of bands detected in the high-resolution polyacrylamide-gradient electrophoresis (dos Santos, 2017), so that, clean (single-peaks) chromatograms tend to associate with $\leq 5$ bands, whereas mixed chromatograms correlates well with $\geq 6$ restriction fragments (see Results). 


\section{Results}

229

230

231

232

233

234

235

236

237

238

239

240

241

242

243

244

245

246

247

248

249

250

251

252

253

254

255

256

257

258

259

260

261

262

263

264

265

266

267

A total of 65 culturable endophytic isolates obtained from cacao pulp adhered to seeds (da Silva, 2013) were considered in this study. Their DNA was individually extracted and subjected to PCR amplification with specific primers targeting the V5-V9 hypervariable region of the $16 \mathrm{~S}$ rDNA (799F and U1492R, Chelius and Triplett, 2001). Each isolate generated a single PCR amplicon (electrophoretic band) that were individually sequenced in a direct manner (Sanger method), after purification from the gel. Under these conditions, no apparent unspecific amplification was observed in the gel for all samples. The preliminary identification of isolates, patterns of chromatogram obtained, and levels of sequence identity revealed by the BlastN are summarized in Table 1. The electropherograms from the $16 \mathrm{~S}$ rDNA sequences presented two major patterns (Fig. 1): 15 isolates showed clear, single-peaks electropherograms of high quality sequences ('clean'), whereas 50 presented mixed eletropherograms, with variable number and intensity of peaks underneath the main base-called sequences subjected to BlastN (Table 1). When the $A l u \mathrm{I}$ restriction analysis was performed on the same PCR-amplified and gel-purified amplicons from the endophytic isolates, all but one of the clean sequences $(93.3 \%$, Table 1) presented the expected electrophoretic pattern of fragments, according to the number of AluI sites identified in silico for those sequences (Fig. 1).

In silico analysis for the AluI sites of the mixed electropherograms could not be done safely, due to the uncertainty of their base-called sequences (Table 1); hence, the number of restriction fragments generated was assessed by electrophoresis only. For these 50 mixed sequences, the majority of $A l u \mathrm{I}$ restriction patterns (63.3\%) showed $\geq 6$ bands (Fig. 1). A chisquare analysis $\left(2 \times 2\right.$ contingency table) was performed to test the null hypothesis $\left(\mathrm{H}_{\mathrm{o}}\right)$ of independence between the 'number of $A l u \mathrm{I}$ fragments' ( $\leq 5$ or $\geq 6$ bands) and the 'type of sequence' (single or mixed). The results $\left(\chi^{2}=12.968 ; P=0.0003\right)$ allowed to reject $\mathrm{H}_{0}$, thereby indicating that the number of $A l u \mathrm{I}$ restriction fragments was essentially dependent upon the type of chromatogram obtained. Interestingly, in certain cases of mixed sequences, possible indels in the 16S rRNA genes have apparently generated mixed templates detectable from specific points in the electropherogram (Fig. 2)(Chen et al., 2015). From a visual inspection and alignment, indels could be identified between the main and the underneath sequences, although the nucleotide signals for the latter were of such a lower level that further fluorescence-background interference prevented their safe detection. In the example shown (Fig. 2), the main base-called sequence was $99 \%$ identical to a Bacillus strain, whereas the underneath sequence dropped the identity to $96 \%$ closest to a Paenibacillus strain. These results strongly indicated the presence of intracell heterogeneity for the 16S rDNA for that particular isolate. Obviously, the observation of clean or mixed chromatograms (which pointed to unique or multiple templates, respectively) did not allow any inference about the number of copies of the 16S rRNA gene present in the organism.

To verify whether the strains retrieved by the BlastN search also show evidence of different 16S rRNA genes in fully sequenced genomes of the same species, an in silico analysis

Peer) reviewing PDF | (2019:02:35420:1:1:NEW 26 Jun 2019) 
268

269

270

271

272

273

274

275

276

277

278

279

280

281

282

283

284

285

286

287

288

289

290

291

292

293

294

295

296

297

298

299

300

301

302

303

304

305

306

was performed with the 15 clean and the 2 mixed sequences showing 99\% identity to database entries (see Table 1). These sequences were chosen due to their safer taxonomic identification, resulting from clearer and undoubtful base-called sequences that provided the highest cover and identity percentages when aligned with GenBank entries (Table 1, Fig. 1). From those 17 safe sequences, we were able to identify 11 deposited strains with fully sequenced genomes from 4 bacterial species: Bacillus thuringiensis, B. pumilus, Gluconobacter oxydans and Staphylococcus epidermidis (Fig. 3). The results showed a range of 1 to 7 aligned copies of 16S rRNA gene that were different from each other and from our isolates. Most of the variations were base substitutions, but deletions and duplications were also identified (Fig. 3). Interestingly, a copy of 16S rRNA gene within the genome of the B. pumilus strain CP009108.1 showed an insertion of 14 bp not shared by the other 7 copies, nor by our isolate ' 23 ', which made it only $97 \%$ identical to them (Fig. 3b). It is also noteworthy that, for most of the clean-chromatogram's isolates subjected to BlastN, the corresponding list of hits depicted from 7 to 51 different species with nucleotide identities $\geq 98 \%$, thus providing a series of distinct genera/spp as possible candidates for taxonomic definition of an isolate, based on this $16 \mathrm{~S}$ rDNA region.

\section{Discussion}

Sequences of 16S rRNA gene have long been used for identification of prokaryotic organisms (Srinivasan et al., 2015), at least in a preliminary manner. However, the intragenomic variation naturally present for this gene, both quantitatively (number of copies) and qualitatively (different DNA sequences), has been adding complexity to this matter (Coenye and Vandamme, 2003; Sun et al., 2013; Chen et al., 2015; Valdivia-Anistro et al., 2016). Due to the extensive use of 16S rRNA gene sequences for taxonomy, phylogenetics and metagenomics, for both culturedependent and -independent methods, the assessment of the extent of these heterogeneities in natural populations appears as an important issue (Pei et al., 2010; Michon et al., 2010). Knowing the levels of intragenomic variation (i) in individual bacterial strains, (ii) in a genus or species, or (iii) in more diverse ecosystems (e.g. water, soils, plants, animals and humans' microbiomes) would help researchers to adjust biodiversity estimates of populations/communities based on $16 \mathrm{~S}$ rDNA sequences, as well as to choose which rDNA region is more appropriate to use for taxonomic identification purposes (Sun et al., 2013; Chen et al., 2015). In the present study, previously isolated endophytic bacteria from cacao seeds (da Silva, 2013; dos Santos, 2017) were used as a model system to address levels of intragenomic variation of this proxy gene in a natural population from a tropical environment. The assessment of an electropherogram profile from direct Sanger sequencing of rDNA-amplified fragment from a single culturable bacterial isolate, coupled with a frequent-cutter $(A l u \mathrm{I})$ restriction analysis of the amplicon, could serve properly as a first-tier indication of intragenomic heterogeneity in the $16 \mathrm{~S}$ rRNA gene. In this case, the frequent-cutter restriction analysis was able to properly replace

Peer] reviewing PDF | (2019:02:35420:1:1:NEW 26 Jun 2019) 
307 the need of cloning and re-sequencing the PCR amplicons (e.g. Chen et al., 2015) to confirm the

308

309

310

311

312

313

314

315

316

317

318

319

320

321

322

323

324

325

326

327

328

329

330

331

332

333

334

335

336

337

338

339

340

341

342

343

344

345

346

multiple template condition.

The results obtained from the combined analyses of electropherograms and AluI restriction patterns (Fig. 1, Table 1) showed that clean chromatograms tend to be indicative of a unique template (with the number of restriction fragments in electrophoresis agreeing with the number of $A l u \mathrm{I}$ sites seen in silico), whereas the mixed ones indicate more than a single template (frequently with $\geq 6 \mathrm{AluI}$ bands) present in the sequenced amplicon. These results, which were fully supported by the chi-square analysis, is in close agreement with previous work with polymicrobial (Kommedal et al., 2008) and with clinical strictly anaerobical samples (Chen et al., 2015). The number of underneath peaks varied among mixed sequences, which may correspond to the number of templates available (only one underneath peak suggests two distinct templates; two underneath peaks, three templates, and so on; Kommedal et al., 2008).

The generally much lower identities $(\leq 96 \%)$ obtained from 47 mixed sequences (Table 1) were likely due to the overlapping electropherograms that generated a lot of confounding signals for base calling, and so, likely formed "chimeric sequences" (in addition to those potentially formed as a PCR-sequencing artifacts; Haas et al., 2011) that far departed from any previously described organism. Contrariwise, the $\geq 98 \%$ identity with database entries found for three mixed sequences (Table 1) can be explained by a lower-intensity signal of the secondary (underneath) peaks, which did not significantly disturb the base calling process. Under these circumstances, such mixed electropherograms in several microbial studies (that have likely not been reported) may have been mistakenly overlooked or discarded as either poor sequencing or isolate contamination (Chen et al., 2015), when, in fact, they might have been indicative of intragenomic heterogeneity in $16 \mathrm{~S}$ rDNAs.

A relevant result from our sampling of culturable endophytes from cacao was the high percentage of intragenomic variation for the 16S rRNA gene in this type of environmental community of culturable bacteria (Table 1). Out of the 65 isolates under study, at least 32 (49.2\%) showed a mixed chromatogram coupled with an $A l u \mathrm{I}$ restriction pattern of $\geq 6$ fragments, which safely detected more than a single template in the corresponding 799F/U1492R PCR amplicon. Considering the tropical origin of these isolates, this result suggests that part of the high levels of microbial diversity in these regions on Earth (Arnold et al., 2002; Strobel and Daisy, 2003; Duarte et al., 2013) is likely due to higher levels of genetic variability and gene transfer among bacteria (Schouls et al., 2003; Zhaxybayeva et al., 2006; Jensen et al., 2009; Kitahara and Miyazaki, 2013). An alternative possibility, though, that the culture medium used for isolation might have favored those bacteria with intrinsically higher rates of mutation/gene transfer cannot be ruled out. A common technical, though simplistic view for mixed chromatograms/sequences is that they result from contamination, due to certain associations of bacteria that are more difficult to separate by standard microbiological techniques, i.e., the case of syntrophs (Caldwell, 1995; Sanders, 2012). Nevertheless, such possibility is not expected to account for so many cases, mainly when very careful procedures for single-colonies isolation were employed throughout (see methods), and considering that endophytes do not tend to form

Peer) reviewing PDF | (2019:02:35420:1:1:NEW 26 Jun 2019) 
347

348

349

350

351

352

353

354

355

356

357

358

359

360

361

362

363

364

365

366

367

368

369

370

371

372

373

374

375

376

377

378

379

380

381

382

383

384

385

386

syntrophic associations, due to the mostly aerobic growth conditions in planta (Morris et al., 2013). Therefore, it is fair to assume that contamination/syntrophy are likely not contributing to the results in a decisive manner (Chen et al., 2015). In addition, completely sequenced genomes in databases show that intragenomic 16S rDNA heterogeneity is not rare in Bacteria, with different levels and types of variation being taxon-dependent (Sun et al., 2013; Chen et al., 2015; Valdivia-Anistro et al., 2016); the same bacterial cell may have up to 15 copies of the 16S rRNA gene, and more than 2-3 types of sequences (Fig. 3)(Klappenbach et al., 2001; Jensen et al., 2009; Liu et al., 2015). Hence, such a condition of intragenomic 16s rDNA variation ought to be more careful addressed and considered, as it has direct consequences for species identification and analyses of richness, abundance and composition of bacterial communities in environmental samples (Coenye and Vandamme, 2003; Pei et al., 2010; Tian et al., 2015). Improved fitness to environmental stresses has been suggested as a driver for higher number and types of 16s rDNA in bacterial genomes (López-López et al., 2007; Jensen et al., 2009; Chen et al., 2015), although these relationships are the likely result of a complex multi-factorial interaction (Valdivia-Anistro et al., 2016).

The approach here presented did show some limitations in identifying the 16S rDNA intragenomic heterogeneity. The fact that $36 \%$ of the mixed-sequences isolates showed a number of restriction fragments compatible to clean ones (Table 1) suggests that other interfering factors leading to mixed-type chromatograms have also occurred. Several technical aspects that can add experimental variability to chromatograms/restriction analyses are, for instance, (i) quality of the gel-purified PCR amplicon sent to sequencing; (ii) potential presence of non-specific priming sites; (iii) quality/consistency of the sequencing procedure, including signal strength, basecalling sensitivity and PCR-derived chimeric sequence formation (Haas et al., 2011); (iv) possible mutation(s) during PCR amplification or bacterial culture (Martinez and Baquero 2000); (v) occasional V5-V9 regions with a single or none AluI site that can lead to mixed chromatograms with $\leq 5$ bands (Ashby et al., 2007); and (vi) occasional incomplete restriction digestion for certain sequences, as the conditions for full digestion (DNA and enzyme amounts, digestion time and temperature) vary among DNA structures/sequences and extracted biological samples. It is noteworthy that the efficiency/completeness of a type IIP enzyme digestion (such as $A l u \mathrm{I})$ depends on specific sequences around the restriction sites and/or proximity between sites in a single DNA molecule (Armstrong and Bauer, 1982; Alves et al., 1984; Pingoud and Jeltsch, 2001). The latter condition is a possible explanation for the pattern of $\geq 6$ bands obtained for one clean-electropherogram isolate (Table 1), since analysis of its V5-V9 sequence revealed two of the AluI sites located less than $17 \mathrm{bp}$ apart. Alternatively, other restriction enzymes can be used in the attempt to solve issues of this nature (e.g. Stakenborg et al., 2005; Jensen et al., 2009; dos Santos, 2017). Once the technical aspects are addressed properly, the approach here employed can provide useful insights concerning the presence of $16 \mathrm{~S}$ rDNA variation in natural populations at a first-tier level.

In the scope of ecology, diversity and evolution studies, certain aspects concerning intragenomic variability of $16 \mathrm{~S}$ rDNA are important to highlight. It has been indicated that $<$ 
387

388

389

390

391

392

393

394

395

396

397

398

399

400

401

402

403

404

405

406

407

408

409

410

411

412

413

414

415

416

417

418

419

420

421

422

423

424

425

426

97\% identity between two 16S rRNA gene sequences is an indicative of different bacterial species (Gevers et al., 2005; Janda and Abbot, 2007). Interestingly, from our results, at least two different 16S rRNA gene sequences present in a single genome can account for differences higher than 3\% identity (Figs. 2 and 3). Indeed, other authors have reported variations as high as 9.7\% among the copies of 16S rDNA (e.g. Pei et al., 2010; Sun et al., 2013). This situation of cells containing heterologous 16S rRNA genes (Asai et al., 1999) is not so unexpected, as it can occur by horizontal transfer of complete operons between bacteria of the same or different species through transformation, conjugation and transduction (Armougom et al., 2009; Smillie et al., 2010; Arber, 2014); studies have shown that Bacillus is a genus specially rich in terms of strains/cells harboring different types and copy number of rRNA operons (Liu et al., 2015), with such a variability being likely relevant for its wide niche occupancy (Valdivia-Anistro et al., 2016 and references therein).

Therefore, analysis of unculturable populations from environmental samples through $16 \mathrm{~S}$ rDNA sequencing may lead to a relevant overestimation of the community diversity and composition (Pei et al., 2010; Haas et al., 2011; Sun et al., 2013; Chen et al., 2015), as different copies of this gene, although originating from the same cell, can match to different species in the database (Fig. 2). Our results suggest that assessments of microbial diversity from any environment, even if based upon high-throughput molecular techniques (e.g. Sinclair et al., 2015), may benefit from also obtaining culturable isolates to investigate the overall levels of their 16S rDNAs intragenomic heterogeneity. The concomitant use of a variety of different media (e.g. those focusing on culturing of specific bacterial subsets of interest; López-López et al., 2007; Jensen et al., 2009; Michon et al., 2010; Tchinda et al., 2016) could help minimizing possible culturing biases of using a single-type medium, thereby providing more representative samplings. In this context, diversity overestimations of culture-independent methods can be somehow more precisely compensated. For instance, finding a given proportion of culturable isolates displaying such intragenomic variability (from a set of properly chosen media) could be applied to correct the OTUs diversity estimation found by a high-throughput molecular approach in the same sample. Depending on the previous knowledge existing in a study system, the information on OTUs overestimations provided by Sun et al. (2013) can be used with the overall approach presented here, which may further help in devising diversity-compensation strategies.

\section{Conclusions}

In conclusion, the coupling of direct Sanger sequencing with restriction enzyme analysis on PCR-purified DNA from culturable isolates was capable to consistently reveal intragenomic $16 \mathrm{~S}$ rDNA heterogeneity in endophytic culturable populations of bacteria. To our knowledge, this is a pioneer report assessing this issue in bacteria inhabiting cacao fruits/seeds, which can be viewed as a relevant representative of tropical environments for endophytes. Despite that full-genome sequencing is the most accurate way to verify such a intragenomic variability, this strategy

Peer) reviewing PDF | (2019:02:35420:1:1:NEW 26 Jun 2019) 
427 depends on specific conditions of logistics or facilities for the laboratories worldwide. The 428 approach presented here combined simple and classical procedures that can fast detect 429 intragenomic variation in $16 \mathrm{~S}$ rDNAs at a first-tier level in any bacterial population. This appears 430 as an alternative not only for initial fingerprinting of isolates in culturable collections, but also to 431 investigate microbial ecology and biodiversity in an array of environments.

432

433

434

435

436

437

438

439

440

441

442

443

444

445

446

447

448

449

450

451

452

453

454

455

456

457

458

459

460

461

462

463

464

465

466

467

468

469

\section{Acknowledgements}

The authors are grateful to State University of Santa Cruz (UESC) for the infrastructure provided. The authors also wish to sincerely thank the anonymous reviewers who have contributed significantly to the improvement of the final version of the manuscript.

\section{References}

Agler, M.T., Ruhe, J., Kroll, S., Morhenn, C., Kim, S-T., Weigel, D., and Kemen, E.M. (2016) Microbial Hub Taxa Link Host and Abiotic Factors to Plant Microbiome Variation. PLoS Biol 14: e1002352.

Alves, J., Pingoud, A., Haupt, W., Langowski, J., Peters, F., Maass, G., and Wolff, C. (1984) The influence of sequences adjacent to the recognition site on the cleavage of oligodeoxynucleotides by the EcoRI endonuclease. Eur J Biochem 140: 83-92.

Andreote, F.D., Gumiere, T., and Durrer, A. (2014) Exploring interactions of plant microbiomes. Sci Agric 71: 528-539.

Arber, W. (2014) Horizontal gene transfer among bacteria and its role in biological evolution. Life 4: 217-224.

Armougom, F., and Raoult, D. (2009) Exploring Microbial Diversity Using 16S rRNA HighThroughput Methods. J Comput Sci Syst Biol 2: 74-92.

Armstrong, K., and Bauer, W.R. (1982) Preferential site-dependent cleavage by restriction endonuclease PstI. Nucl Acid Res 10: 993-1007.

Arnold, A.E., Maynard, Z., Gilbert, G.S., Coley, P.D., and Kursar, T.A. (2002) Are tropical fungal endophytes hyperdiverse? Ecol Lett 3: 267-274.

Arnold, A.E., and Lutzoni, F. (2007) Diversity and host range of foliar fungal endophytes: are tropical leaves biodiversity hotspots? Ecology 88: 541-549.

Asai, T., Zaporojets, D., Squires, C., and Squires, C.L. (1999) An Escherichia coli strain with all 
470

471

472

473

474

475

476

477

478

479

480

481

482

483

484

485

486

487

488

489

490

491

492

493

494

495

496

497

498

499

500

501

502

503

504

505

506

507

508

509

510

511

512

513

514

515

chromosomal rRNA operons inactivated: complete exchange of rRNA genes between bacteria. Proc Natl Acad Sci USA 96: 1971-1976.

Ashby, M.N., Rine, J., Mongodin, E.F., Nelson, K.E., and Dimster-Denk, D. (2007) Serial analysis of rRNA genes and the unexpected dominance of rare members of microbial communities. Appl Environ Microbiol 73: 4532-4542.

Barrow, J.R., Lucero, M.E., Reyes-Vera, I., and Havstad, K.M. (2008) Do symbiotic microbes have a role in plant evolution, performance and response to stress? Commun Integr Biol 1: 69-73.

Beg, M.S., Ahmad, S., Jan, K., and Bashir, K. (2017) Status, supply chain and processing of cocoa - A review. Trends Food Sci Technol 66: 108-116.

Berg, G., Köberl, M., Rybakova, D., Müller, H., Grosch, R., and Smalla, K. (2017) Plant microbial diversity is suggested as the key to future biocontrol and health trends. FEMS Microbiol Ecol 93: fix050.

Brown, D.D., Wensink, P.C., and Jordan, E. (1972) A comparison of the ribosomal DNA's of Xenopus laevis and Xenopus mulleri: the evolution of tandem genes. J Mol Biol 63: 57-73.

Bulgarelli, D., Schlaeppi, K., Spaepen, S., Ver Loren van Themaat, E., and Schulze-Lefert, P. (2013) Structure and functions of the bacterial microbiota of plants. Annu Rev Plant Biol 64: 807-838.

Bull, A.T. (2004) How to look, where to look. In Microbial Diversity and Bioprospecting. Bull, A.T. (ed). Washinton D.C.: ASM Press, pp. 71-79.

Caldwell, D.E. (1995) Cultivation and study of biofilm communities. In Microbial Biofilms. Lappin-Scott, H.M., and Costerton, J.E. (eds). Cambridge: Cambridge University Press, pp. 64-79.

Clarridge, J.E. (2004) Impact of 16S rRNA gene sequence analysis for identification of bacteria on clinical microbiology and infectious diseases. Clin Microbiol Rev 17: 840-862.

Chelius, M.K., Triplett, E.W. (2001) The diversity of Archaea and Bacteria in association with the roots of Zea mays L. Microbial Ecol 41: 252-263.

Chen, J., Miao, X., Xu, M., He, J., Xie, Y., Wu X., Chen, G., Yu, L., Zhang, W. (2015) Intragenomic heterogeneity in $16 \mathrm{~S}$ rRNA genes in strictly anaerobic clinical isolates from periodontal abscesses. PLoS One 10: 1-19.

Coenye, T., and Vandamme, P. (2003) Intragenomic heterogeneity between multiple 16S ribosomal RNA operons in sequenced bacterial genomes. FEMS Microbiol Lett 228: 45-49.

Crozier, J., Thomas, S.E., Aime, M.C., Evans, H.C., and Holmes, K.A. (2006) Molecular

Peer] reviewing PDF | (2019:02:35420:1:1:NEW 26 Jun 2019) 
516

517

518

519

520

521

522

523

524

525

526

527

528

529

530

531

532

533

534

535

536

537

538

539

540

541

542

543

544

545

546

547

548

549

550

551

552

553

554

555

556

557

558

559

560

561

characterization of fungal endophytic morphospecies isolated from stems and pods of Theobroma cacao. Plant Pathol 55: 783-791.

da Silva, C.B. (2013) Cacao holobiont: genetic diversity of the microbial portion associated with fruits of different clones of Theobroma cacao L., Master's Thesis. Ilhéus-BA, Brazil: State University of Santa Cruz (UESC).

Das, S., Dash, H.R., Mangwani, N., Chakraborty, J., and Kumari, S. (2014) Understanding molecular identification and polyphasic taxonomic approaches for genetic relatedness and phylogenetic relationships of microorganisms. J Microbiol Methods 103: 80-100.

Donald, P.F. (2004) Biodiversity impacts of some agricultural commodity production systems. Conserv Biol 18: 17-37.

dos Santos, H.M.R. (2017) Artificially constituted bacterial communities: ARDRA as a case study on 16S rDNA PCR limitations for endophytic diversity analysis, and use of Virola officinalis as an experimental model, Doctoral Dissertation. Ilhéus-BA, Brazil: State University of Santa Cruz (UESC).

Doyle, J., and Doyle JL. (1987) A rapid DNA isolation procedure for small quantities of fresh leaf tissue. Phytochem Bull 19: 11-15.

Duarte, E.A., Lacerda Jr, G.V., de Oliveira, T.A., Brendel, M., Loguercio, L.L., Cascardo, J.C. (2013) Bioprospection of bacteria and yeasts from Atlantic Rainforest soil capable of growing in crude-glycerol residues. Genet Mol Res 12: 4422-4433.

Eardly, B.D., Wang, F-S., and van Berkum, P. (1996) Corresponding 16S rRNA gene segments in Rhizobiaceae and Aeromonas yield discordant phylogenies. Plant Soil 186: 69-74.

Engene, N., and Gerwick, W.H. (2011) Intra-genomic 16S rRNA gene heterogeneity in cyanobacterial genomes. Fottea 1: 17-24.

Gevers, D., Cohan, F.M., Lawrence, J.G., Spratt, B.G., Coenye, T., Feil, E.J., Stackebrandt. E., Van de Peer, Y., Vandamme, P., Thompson, F.L., Swings, J. (2005) Opinion: Re-evaluating prokaryotic species. Nat Rev Microbiol 3: 733-739.

Gouda, S., Das, G., Sen, S.K., Shin, H.S., and Patra, J.K. (2016) Endophytes: A Treasure House of Bioactive Compounds of Medicinal Importance. Front Microbiol 7: 1538.

Haas, B.J., Gevers, D., Earl, A.M., Feldgarden, M., Ward, D.V., Giannoukos, G. et al. (2011) Chimeric 16S rRNA sequence formation and detection in Sanger and 454-pyrosequenced PCR amplicons. Genome Res 21: 494-504.

Hanada, R.E., Pomella, A.W.V., Costa, H.S., Bezerra, J.L., Loguercio, L.L., and Pereira, J.O. (2010) Endophytic fungal diversity in Theobroma cacao (cacao) and T. grandiflorum (cupuaçu) trees and their potential for growth promotion and biocontrol of black-pod

Peer) reviewing PDF | (2019:02:35420:1:1:NEW 26 Jun 2019) 
562

563

564

565

566

567

568

569

570

571

572

573

574

575

576

577

578

579

580

581

582

583

584

585

586

587

588

589

590

591

592

593

594

595

596

597

598

599

600

601

602

603

604

605

606

607

disease. Fungal Biol 114: 901-910.

Hardoim, P.R., van Overbeek, L.S., Berg, G., Pirttilä, A.M., Compant, S., Campisano, A. et al. (2015) The hidden world within plants: ecological and evolutionary considerations for defining functioning of microbial endophytes. Microbiol Mol Biol Rev 79: 293-320.

Hartmeier, G.N., and Justesen, U.S. (2010) Direct 16S rRNA gene sequencing of polymicrobial culture-negative samples with analysis of mixed chromatograms. J Med Microbiol 59: 486488.

Janda, J.M., and Abbott, S.L. (2002) Bacterial identification for publication: when is enough enough? J Clin Microbiol 40: 1887-1891.

Janda, J.M., and Abbott, S.L. (2007) 16S rRNA Gene Sequencing for Bacterial identification in the diagnostic laboratory: pluses, perils, and pitfalls. J Clin Microbiol 45: 2761-2764.

Jensen, S., Frost, P., and Torsvik, V.L. (2009) The nonrandom microheterogeneity of 16S rRNA genes in Vibrio splendidus may reflect adaptation to versatile lifestyles. FEMS Microbiol Lett 294: 207-215.

Kitahara, K., and Miyazaki, K. (2013) Revisiting bacterial phylogeny: Natural and experimental evidence for horizontal gene transfer of 16S rRNA. Mob Genet Elements 3: e24210.

Klappenbach, J.A., Saxman, P.R., Cole, J.R., and Schmidt, T.M. (2001) rrnDB: the ribosomal RNA operon copy number database. Nucleic Acids Res 29: 181-184.

Kommedal, Ø. (2012) Group Specific Primers. Patent US 2012/0309012A1.

Kommedal, Ø., Karlsen, B., and Sæbø, Ø. (2008) Analysis of mixed sequencing chromatograms and its application in direct $16 \mathrm{~S}$ rRNA gene sequencing of polymicrobial samples. $J$ Clin Microbiol 46: 3766-3771.

Konstantinidis, K.T., Ramette, A., and Tiedje, J.M. (2006) The bacterial species definition in the genomic era. Philos Trans R Soc Lond B Biol Sci 361: 1929-1940.

Leite, H.A.C., Silva, A.B., Gomes, F.P., Gramacho, K.P., Faria, J.C., de Souza, J.T., and Loguercio, L.L. (2013) Bacillus subtilis and Enterobacter cloacae endophytes from healthy Theobroma cacao L. trees can systemically colonize seedlings and promote growth. Appl Microbiol Biotechnol 97: 2639-2651.

Lindner, D.L., Carlsen, T., Henrik Nilsson, R., Davey, M., Schumacher, T., and Kauserud, H. (2013) Employing 454 amplicon pyrosequencing to reveal intragenomic divergence in the internal transcribed spacer rDNA region in fungi. Ecol Evol 3: 1751-1764.

Liu, Y., Lai, Q., Göker, M., Meier-Kolthoff, J.P., Wang, M., Sun, Y., Wang, L., and Shao, Z. (2015) Genomic insights into the taxonomic status of the Bacillus cereus group. Sci Rep 5:

Peer] reviewing PDF | (2019:02:35420:1:1:NEW 26 Jun 2019) 
$608 \quad 14082$.

609

610

611

612

613

614

615

616

617

618

619

620

621

622

623

624

625

626

627

628

629

630

631

632

633

634

635

636

637

638

639

640

641

642

643

644

645

646

647

648

649

650

651

652

653

654

López-López, A., Benlloch, S., Bonfá, M., Rodríguez-Valera, F., and Mira, A. (2007) Intragenomic 16S rDNA divergence in Haloarcula marismortui is an adaptation to different temperatures. J Mol Evol 65: 687-696.

Manaka, A., Tokue, Y., and Murakami, M. (2017) Comparison of 16S ribosomal RNA gene sequence analysis and conventional culture in the environmental survey of a hospital. $J$ Pharm Heal Care Sci 3: 1-6.

Martinez, J.L., and Baquero, F. (2000) Mutation frequencies and antibiotic resistance. Antimicrob Agents Chemother 44: 1771-1777.

Mejía, L.C., Rojas, E.I., Maynard, Z., Van Bael, S., Arnold, A.E., Hebbar, P. et al. (2008) Endophytic fungi as biocontrol agents of Theobroma cacao pathogens. Biol Control 46: 414.

Melnick, R.L., Suárez, C., Bailey, B.A., and Backman, P.A. (2011) Isolation of endophytic endospore-forming bacteria from Theobroma cacao as potential biological control agents of cacao diseases. Biol Control 57: 236-245.

Morris, B.E.L., Henneberger, R., Huber, H., Moissl-Eichinger, C. (2013) Microbial syntrophy: interaction for the common good. FEMS Microbiol Rev 37 (3): 384-406.

Michon, A.L., Aujoulat, F., Roudière, L., Soulier, O., Zorgniotti, I., Jumas-Bilak, E., and Marchandin, H. (2010) Intragenomic and intraspecific heterogeneity in rrs may surpass interspecific variability in a natural population of Veillonella. Microbiology 156: 20802091.

Pei, A.Y., Oberdorf, W.E., Nossa, C.W., Agarwal, A., Chokshi, P., Gerz, E.A. et al. (2010) Diversity of $16 \mathrm{~S}$ rRNA genes within individual prokaryotic genomes. Appl Environ Microbiol 76: 3886-3897.

Pingoud, A., and Jeltsch, A. (2001) Structure and function of type II restriction endonucleases. Nucleic Acids Res 29: 3705-3727.

Rubini, M.R., Silva-Ribeiro, R.T., Pomella, A.W.V., Maki, C.S., Araújo, W.L., Santos, D.R., and Azevedo, J.L. (2005) Diversity of endophytic fungal community of cacao (Theobroma cacao L.) and biological control of Crinipellis perniciosa, causal agent of witches' broom disease. Int J Biol Sci 1: 24-33.

Sanders, E.R. (2012) Aseptic laboratory techniques: plating methods. J Vis Exp 63: 3064.

Sarethy, I.P., Pan, S., and Danquah, M.K. (2014) Modern taxonomy for microbial diversity. In Biodiversity-the dynamic balance of the planet. Grillo, O. (ed). London: In Tech Open, pp. 51-68.

Peer) reviewing PDF | (2019:02:35420:1:1:NEW 26 Jun 2019) 
655

656

657

658

659

660

661

662

663

664

665

666

667

668

669

670

671

672

673

674

675

676

677

678

679

680

681

682

683

684

685

686

687

688

689

690

691

692

693

694

695

696

697

698

699

700

Schouls, L.M., Schot, C.S., and Jacobs, J.A. (2003) Horizontal transfer of segments of the 16S rRNA genes between species of the Streptococcus anginosus group. J Bacteriol 185: 72417246.

Schroth, G., Faria, D., Araujo, M., Bede, L., Van Bael, S.A., Cassano, C.R. et al. (2011) Conservation in tropical landscape mosaics: the case of the cacao landscape of southern Bahia, Brazil. Biodivers Conserv 20: 1635-1654.

Schulz, B., Boyle, C., Draeger, S., and Römmert, A.K. (2002) Endophytic fungi: a source of novel biologically active secondary metabolites. Mycol Res 106: 996-1004.

Schulz, B., and Boyle, C. (2005) The endophytic continuum. Mycol Res 109: 661-686.

Sinclair, L., Osman, O.A., Bertilsson, S., and Eiler, A. (2015) Microbial community composition and diversity via 16s rRNA gene amplicons: evaluating the Illumina Platform. PLoS One 10: e0116955.

Smillie, C., Garcillán-Barcia, M.P., Francia, M.V., Rocha, E.P.C., and de la Cruz, F. (2010) Mobility of plasmids. Microbiol Mol Biol Rev 74: 434-452.

Srinivasan, R., Karaoz, U., Volegova, M., MacKichan, J., Kato-Maeda, M., Miller, S. et al. (2015) Use of 16S rRNA gene for identification of a broad range of clinically relevant bacterial pathogens. PLoS One 10: e0117617.

Stackebrandt, E., and Goebel, B.M. (1994) Taxonomic Note: A place for DNA-DNA reassociation and 16S rRNA sequence analysis in the present species definition in bacteriology. Int J Syst Bacteriol 44: 846-849.

Stakenborg, T., Vicca, J., Butaye, P., Maes, D., De Baere, T., Verhelst, R. et al. (2005) Evaluation of amplified rDNA restriction analysis (ARDRA) for the identification of Mycoplasma species. BMC Infect Dis 5: 46.

Strobel, G., and Daisy, B. (2003) Bioprospecting for microbial endophytes and their natural products. Microbiol Mol Biol Rev 67: 491-502.

Sun, D-L., Jiang, X., Wu, Q.L., and Zhou, N-Y. (2013) Intragenomic heterogeneity of 16S rRNA genes causes overestimation of prokaryotic diversity. Appl Environ Microbiol 79: 59625969.

Tchinda, R.A.M., Boudjeko, T., Simao-Beaunoir, A-M., Lerat, S., Tsala, É., Monga, E., and Beaulieu, C. (2016) Morphological, physiological, and taxonomic characterization of actinobacterial isolates living as endophytes of cacao pods and cacao seeds. Microbes Environm 31: 56-62.

Tian, R.M., Cai, L., Zhang, W.P., Cao, H.L., and Qian, P.Y. (2015) Rare events of intragenus and intraspecies horizontal transfer of the 16S rRNA gene. Genome Biol Evol 7: 2310-2320.

Peer] reviewing PDF | (2019:02:35420:1:1:NEW 26 Jun 2019) 
701

702

703

704

705

706

707

708

709

710

711

712

713

714

715

716

717

718

719

720

721

722

723

724

725
Torsvik, V., Goksoyr, J., and Daae, F.L. (1990) High diversity in DNA of soil bacteria. Appl Environ Microbiol 56: 782-787.

Turner, T.R., James, E.K., and Poole, P.S. (2013) The plant microbiome. Genome Biol 14: 209.

Valdivia-Anistro, J.A., Eguiarte-Fruns, L.E., Delgado-Sapién, G., Márquez-Zacarías, P., GascaPineda, J., Learned, J. et al. (2016) Variability of rRNA operon copy number and growth rate dynamics of Bacillus isolated from an extremely oligotrophic aquatic ecosystem. Front Microbiol 6: 1-15.

Vandamme, P., Pot, B., Gillis, M., de Vos, P., Kersters, K., and Swings, J. (1996) Polyphasic taxomomy, a consensus approach to bacterial systematics. Microbiol Rev 60: 407-438.

Wickramasuriya, A.M., and Dunwell, J.M. (2018) Cacao biotechnology: current status and future prospects. Plant Biotechnol J 16: 4-17.

Woo, P.C.Y., Teng, J.L.L., Yeung, J.M.Y., Tse, H., Lau, S.K., and Yuen, K.Y. (2011) Automated identification of medically important bacteria by 16S rRNA gene sequencing using a novel comprehensive database, 16SpathDB. J Clin Microbiol 49: 1799-1809.

Zhaxybayeva, O., Gogarten, J.P., Charlebois, R.L., Doolittle, W.F., and Papke, R.T. (2006) Phylogenetic analyses of cyanobacterial genomes: quantification of horizontal gene transfer events. Genome Res 16: 1099-1108. 


\section{Table 1 (on next page)}

Approximate identification of culturable endophytic bacterial isolates from cacao, based on direct amplicon sequencing of the 16S rDNA V5-V9 hypervariable region.

${ }^{1}$ An expedite characterization of each culturable endophytic isolate from cacao was performed through direct amplicon sequencing on gel-purified, single-band PCR products of $799 \mathrm{~F} / 1492 \mathrm{U}$ primers, spanning the V5-V9 hypervariable region of $16 \mathrm{~S}$ rDNA. Analysis of the resulting electropherograms indicated two major groups: one with clear, sharp and undoubtedly-single peaks for each nucleotide (high quality sequences), which comprised 15 isolates, within which 93.3\% expectedly showed 3-5 Alul restriction fragments (see Results and Discussion). The other group (mixed-peaks) presented variable levels of background, lowerintensity peaks underneath each nucleotide-read peak (lower quality sequences); this group comprised 50 isolates, within which $64.0 \%$ expectedly showed $\geq 6$ Alul restriction fragments (also see next).

${ }^{2}$ Numbers correspond to the identification of the culturable isolates in the local collection; underlined isolates are those whose Alul restriction patterns departed from the expected number of bands, i.e. $\geq 6$ fragments for the single-peaks group and $\leq 5$ fragments for the mixed-peaks group (see chi-square analysis in the Results text).

${ }^{3}$ Considering the highest score obtained from the BlastN search (with $100 \%$ sequence cover), the species/strains retrieved are shown by the corresponding access number indicated between parenthesis. The lower levels of identity ( $\leq 98 \%$ ) indicated in the right column indicate an increasing interference of the lower-intensity underneath peaks, which generate a "chimeric-sequence" effect in the main base-called reads, thereby departing from the expected $(99-100 \%)$ sequence similarity. 


\begin{tabular}{|c|c|c|c|}
\hline $\begin{array}{l}\text { Electro- } \\
\text { phero- } \\
\text { gram }^{1}\end{array}$ & Isol ${ }^{2}$ & BlastN results ${ }^{3}(\mathrm{sp} / \mathrm{strain})$ & $\begin{array}{c}\text { ident } \\
(\%)\end{array}$ \\
\hline \multirow{3}{*}{$\begin{array}{c}\text { Clean } \\
(15)\end{array}$} & $5, \underline{6}, 18,31$ & $\begin{array}{c}\text { Bacillus cereus LV11 (KU705859.1), B. thuringiensis strain NBRC } \\
101235 \text { (NR112780.1), B. pumilus strain L1 (KT937148.1), B. } \\
\text { safensis strain IHB B 14105 (KM817280.1) }\end{array}$ & 100 \\
\hline & $\begin{array}{l}3,11,23 \\
34,37,38 \\
39\end{array}$ & $\begin{array}{c}\text { Bacillus amyloliquefaciens strain HD34 (KT368090.1), B. pumilus } \\
\text { strain AUCAB16 (JN315777.1), B. pumilus strain NBRC } 12092 \\
\text { (NR112637.1), Bacillus sp. BAB-4112 (KJ778656.1), SMF5 } \\
\text { (AJ868359.1), SW3.2 (KU740234.1), B. stratosphericus strain IHB } \\
\text { B } 6832 \text { (KF668462.1) }\end{array}$ & 99 \\
\hline & $\begin{array}{c}53,57,62 \\
67\end{array}$ & $\begin{array}{c}\text { Gluconobacter nephelii strain LMG } 26773 \text { (NR118638.1), } \\
\text { Lysinibacillus fusiformis strain NBRC } 15717 \text { (NR112628.1), } \\
\text { Raoultella ornithinolytica B6 (CP004142.1), Staphylococcus } \\
\text { pasteuri strain ATCC } 51129 \text { (NR024669.1) }\end{array}$ & \\
\hline
\end{tabular}

40, $63 \quad$ Bacillus stratosphericus strain IHBB 9411 (KR085786.1), Staphylococcus epidermidis strain DAR1907 (CP013943.1)

52 Escherichia coli strain BAB-538 (KF535120.1)

Bacillus pumilus strain IHB B 12534 (KJ767390.1), Lelliottia amnigena strain ZB04 (CP015774.1)

Bacillus sp. SB3.1 (KU740223.1) ; Bacillus australimaris strain MCCC 1A05787 (NR148787.1), B. pumilus (KU922935.1),

Pseudomonas plecoglossicida strain RD_AZLTR_14 (KU597542.1) ; B. altitudinis strain BT 98 (KJ848598.1), B. safensis

$36 ; 13,10$, strain AL-8 (HQ848126.1), Citrobacter sp. BRRO1 (KT735246.1), Mixed $61 ; 1,29$, Enterobacter sp. clone HSL29 (HM461152.1); B. pumilus strain SQU P001 (KU220846.1), B. subtilis strain SRI2 (KP271983.1), (50) $\quad \underline{48}, 51 ; 25$, $\underline{43}, 59,71$; Pantoea agglomerans (DQ392984.1), Uncultured bacterium clone 218002-244 (JQ940965.1) ; B. licheniformis strain KYLS-CU01 $8,24, \underline{27}$, (KF111800.1), B. pumilus strain SH-B9 (CP011007.1), B. pumilus $\underline{46}, \underline{58}, 69$; $33, \underline{44}, 64$, $68 ; 12,30$, $\underline{42}, 55$ strain TP-Snow-C22 (HQ327131.1), Brevibacillus sp. XYY-2015

(KR528483.1), Paenibacillus sp. KMSDS2 (JF768723.1), Staphylococcus lugdunensis strain ATCC 43809 (NR024668.1);

Bacillus sp. 01082 (EU520309.1), B. subtilis strain W1

(KC441816.1), Staphylococcus saprophyticus strain PW64 (KT726989.1), S. warneri strain LEH1_5A (JN644590.1) ; Bacillus pumilus strain C1C5502 (KR677555.1), B. safensis strain FFA38 (JN092820.1), B. subtilis strain SP3 (KT875349.1), Lysinibacillus fusiformis strain BN-4 (JN039176.1)

2, $\underline{60}, 66, \quad$ Bacillus altitudinis strain JF2 (KC171985.1), Pantoea agglomerans 
70, 72; 47, $\quad$ strain A9 (KC434965.1), Staphylococcus sp. CM2E1 49, 50; 26; (KM874434.1), S. warneri strain MBS022 (KT582294.1), Uncultured 45; 32, 41; Lactobacillales bacterium isolate DGGE 6PLAB (GQ911039.1) ; 28; 4, 9; 7, Citrobacter murliniae strain E61 (HQ407238.1), Enterobacter $\underline{16}, \underline{35}, \underline{56} \quad$ (JX081588.1); Bacillus pumilus strain SW-3 (KC813157.1); Bacillus thuringiensis strain Po-5 (JX391979.1); Bacillus safensis strain MUGA141 (KJ672329.1), B. subtilis strain p95_H01 (JQ830651.1) ; Bacillus pumilus strain ZK1 (JQ773350.1) ; Bacillus atrophaeus strain NBF1 (HQ256518.1), B. pumilus (GQ861537.1); Bacillus firmus (EF526504.1), B. pumilus strain IARI-SL-5 (JX645203.1), Bacillus sp. Ob 06 (AJ971891.1), Lysinibacillus sp. TRS6 (KJ617407.1)

1 


\section{Figure 1}

Illustration of electropherograms and restriction profiles resulting from sequencing and Alul digestion of PCR-amplified V5-V9 region of 16S rRNA genes from endophytic bacteria from Theobroma cacao

The procedure was applied to 65 culturable isolates from cacao seeds + pulp (see text), and the data correspond to six isolates (identified by the numbers on top) that are representative examples. The agarose-gel electrophoretic profiles for single-fragment PCRamplificationswith primers 799F/U1492R are shown on the top. 'Clean' electropherograms, characteristic of unique templates, are shown on the left side, whereas mixed ones, which can indicate multiple templates, appear on the right side. The images of the corresponding gel resulting from the Alul digestion of the same sequence appear next to each chromatogram. The percentage of identity with the best hit retrieved by the BlastN is indicated besides each gel. (The sequences produced from the 65 isolates are provided in a supplementary multi-fasta text file). 


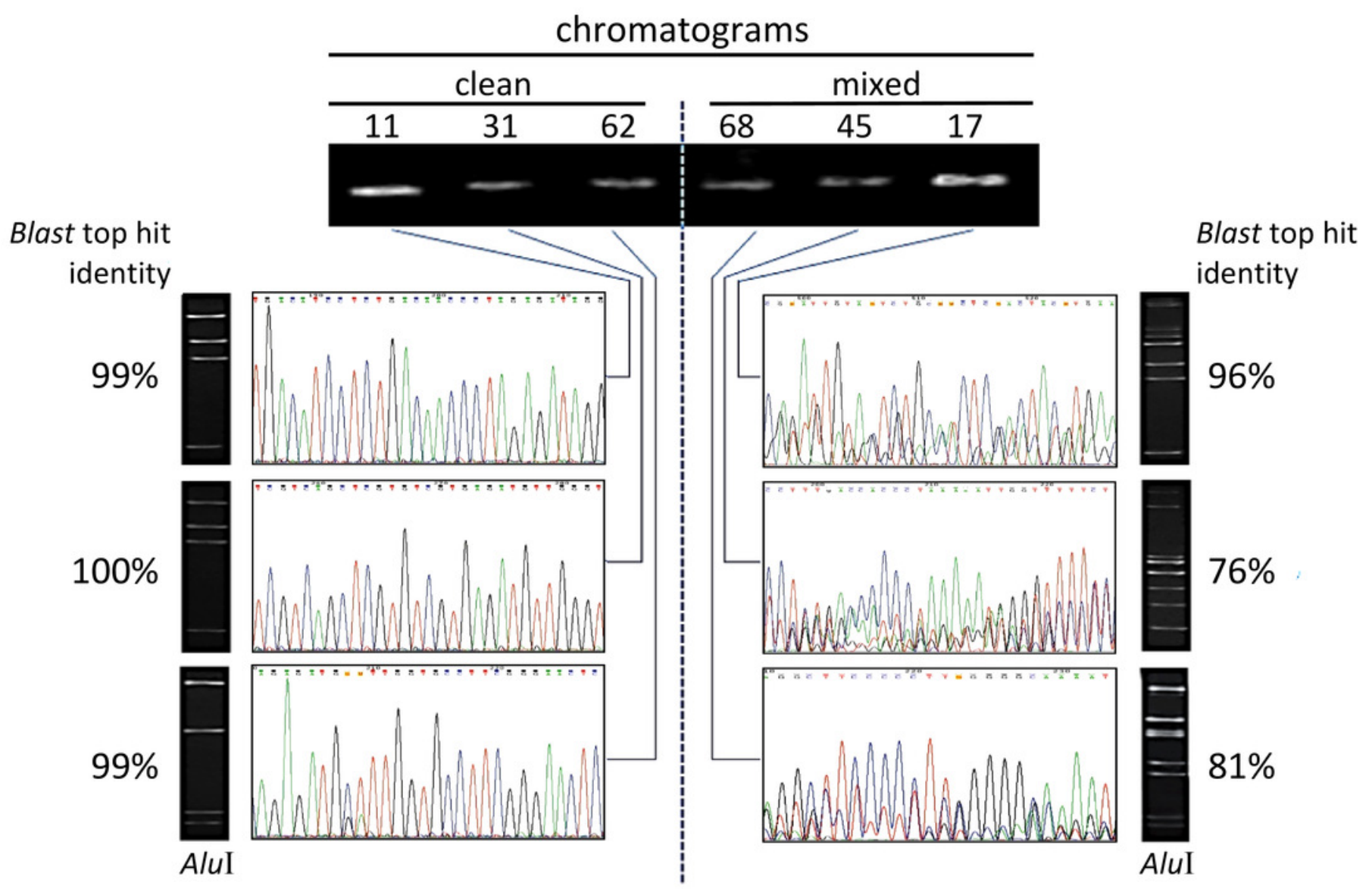




\section{Figure 2}

Example of a double-template mixed electropherogram for a 16S rRNA gene amplicon of an endophytic bacterial isolate from Theobroma cacao.

The region displayed shows specific stretches where a clean pattern changes to a doublesequence electropherogram, indicated by horizontal arrows. The base-called sequence of the respective 16S rRNA gene are given on top of the electropherogram (a), and as the top sequence (capital letters) in the underneath alignment. Visual inspection of peak intensities allowed precise identification of the main and secondary sequences, which were manually aligned as indicated (b). For the stretches where only single peaks were observed, the sequences of the supposed two templates appeared to be the same and are shown as capital letters in a single line. For the aligned 'mixed' stretches 1 and 2 , the top sequence is the main one and the borders of the overlapping stretches are indicated by dashed arrows and the base-pair number (position) of the main sequence; small-caps letters in the main (top) sequence were base-called ambiguities defined by visual inspection of the eletropherogram. The secondary sequence was predominantly shown in small-caps, except for those bases with only a single peak (capital letters). The two sequences alignment was optimized manually, in which dashes were introduced in each sequence for the best possible adjustment. Dots and stars underneath the alignment correspond to matches and mismatches, respectively; question marks indicate points were the secondary-sequence signals were too low and it was not possible to discern them from background; bold ' $g$ ' letters and dashes suggest potential indels between the two sequences. The sequences definition and alignment could be undoubtedly done up to the 468 bp only. 

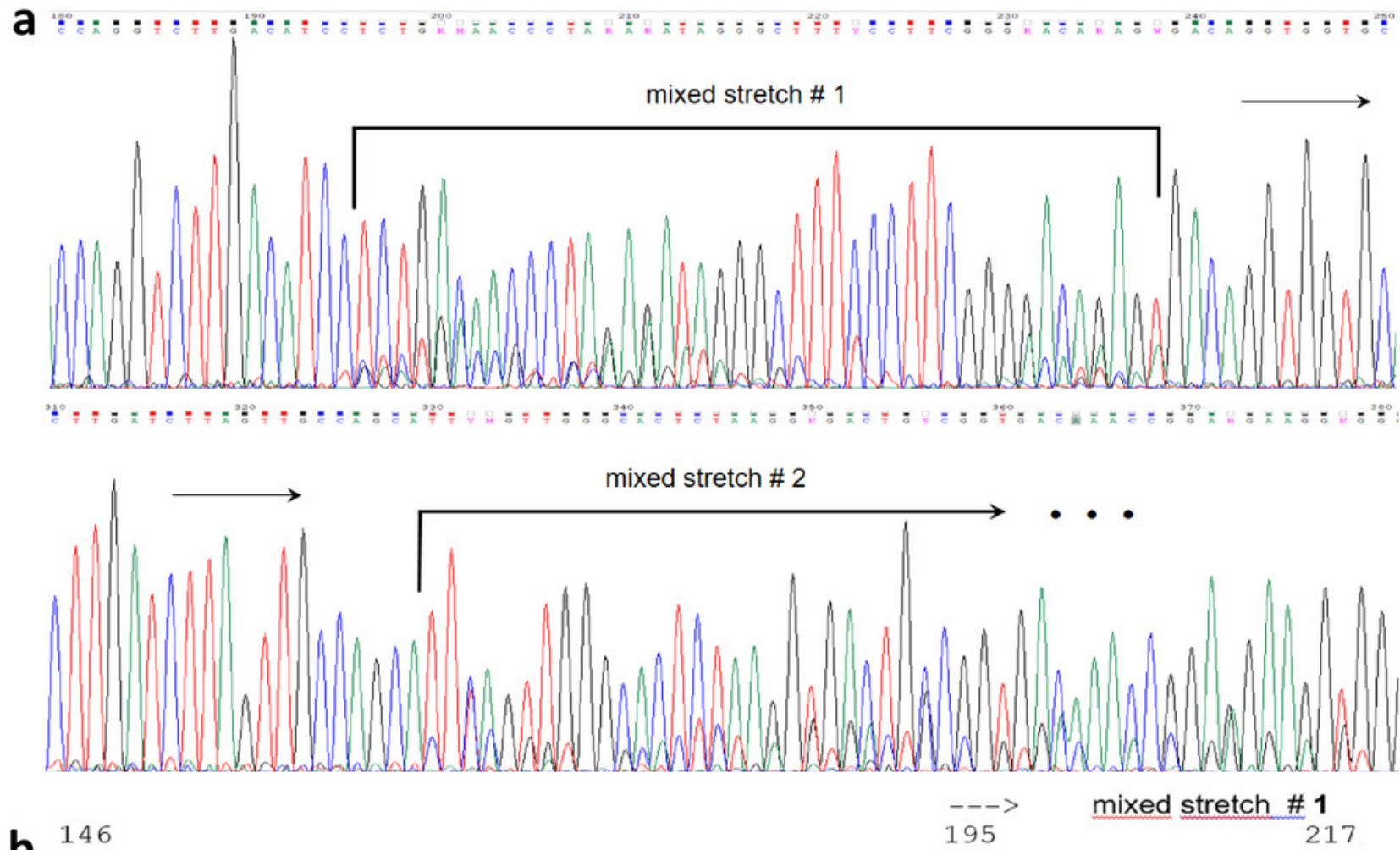

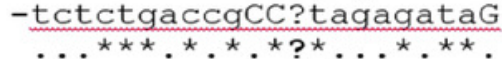

218 $<---$

289

-CTTTCCCTTCGGGgACARAGtGACAGGTGGTGCATGGTTGTCGTCAGCTCGTGTCGTGAGATGTTGGGTTAA gcTTt-CCTTCGGG-acata?aa

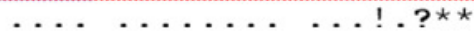

$290 \quad 329 \quad$ mixed stretch \# 2

GTCCCGCAACGAGCGCAACCCTTGATCTTAGTTGCCAGCATTCaGT-TGGGCACTCTAAGGtGACTGCCGGT $\frac{\text { CTccGggtGGgcactctAaGgtgactaCcGgt }}{\star \cdots * *^{\star} \ldots \ldots \ldots \ldots \ldots \ldots \ldots \ldots \ldots \ldots}$

361

432

GACAAACCGGAgGAAGGtGGGGATGACGTCaAATCATCaTGCCCCTTATGACCTGGGCTACCCACGTGCTAC gacAAaCcGgRGgAaGgtGGGgatgacgtcAAatcatcatgCCCcttatgaCctGGgctacacacgtactac

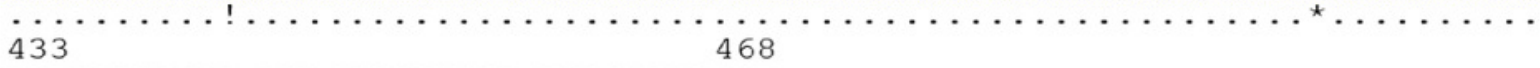

AATGGACAGAACAAAGGGCTGCGAgACCGCAAGGTT

AatGgCcGgtacAAcGGgctgtgaggCcgcgaGgTg $(-->\ldots)$

$\ldots \ldots{ }^{\star}{ }^{*} \cdot{ }^{\star} \ldots{ }^{*} \ldots \ldots{ }^{*} \ldots{ }^{*} \ldots{ }^{*} \ldots{ }^{*}$ 


\section{Figure 3 (on next page)}

Intragenomic variation of the 16S rRNA gene from bacterial species with their complete genome deposited at GenBank, identified by the BlastN search with sequences from endophytic isolates from Theobroma cacao.

Only the 15 undoubtful, clean sequences and the two mixed sequences with $99 \%$ identity (Table 1) were considered. The indicated genomes (species names in grey boxes) were found by BlastN with the isolates \# 6 (a), 23 (b), 53 (c) and 63 (d), which were indicated in bold as the reference sequence used in each of the 11 alignments shown. The identification and access numbers of the corresponding strains with genomes fully sequenced is indicated on top of each alignment group. In each of these groups, the letters $A, B, C$ etc on the left column correspond to the different types of 16S rRNA gene sequences found in the genome, with the number of copies of each type shown between parenthesis besides them. The numbers in the first line (out of scale) correspond to the base-pair positions of the cacao isolate sequence where differences were found among the sequence types. The asterisk $(*)$ sign indicate bp matches in the whole stretches compared to the reference sequence (cacao isolate) on top of each alignment group. The percentage of sequences identity with respect to the cacao isolates is shown between parenthesis on the right side of each sequence. For the second alignment group of Bacillus pumilus (isolate 23), the stretch of 'zeros' on the reference sequence indicate a large gap in relation to the ' $F$ ' sequence (the gap is present in all sequence types, from ' $A$ ' to ' $E$ '). 


\section{PeerJ}

\section{a Bacillus thuringiensis}

konkukian str. 97-27 (14) NC_005957.1

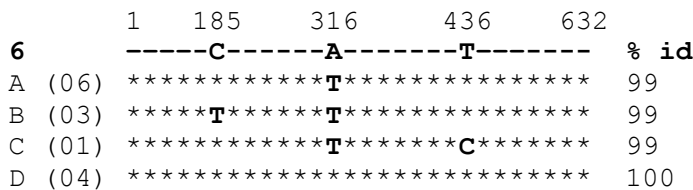

finitimus YBT-020 (14) NC_017200.1

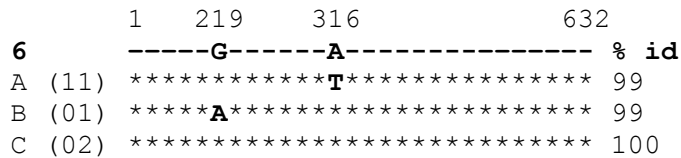

BM-BT15426 (14) NZ_CP020723.1

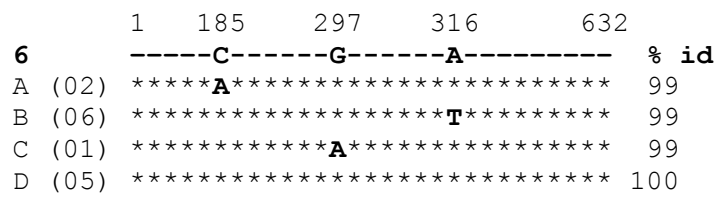

\section{b Bacillus pumillus}

W3 (7) NZ_CP011150.1

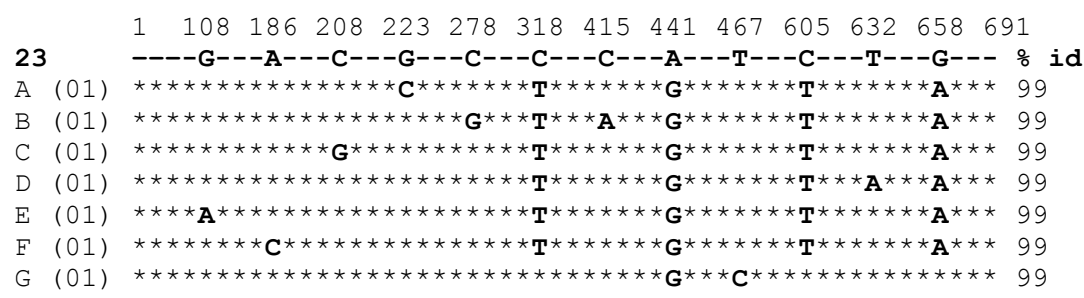

GR-8 (8) NZ_CP009108.1

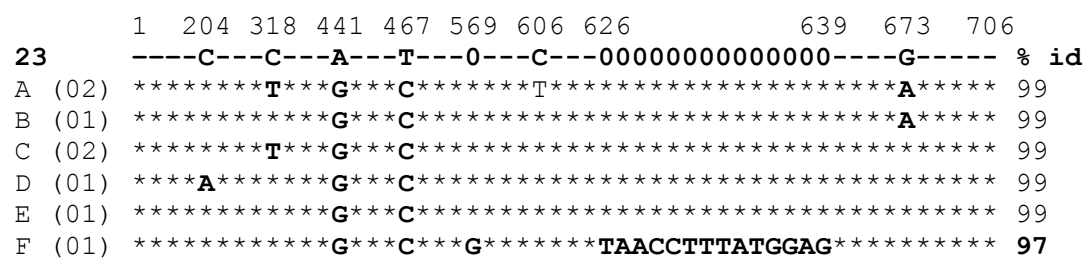

TUAT1 (8) NZ_AP014928.1

\begin{tabular}{|c|c|}
\hline & 1 \\
\hline 23 & $----\mathrm{C}---\mathrm{C}---\mathrm{A}---\mathrm{T}----\frac{\circ}{0}$ id \\
\hline A $(04)$ & 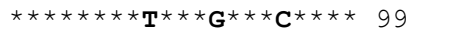 \\
\hline (01) & 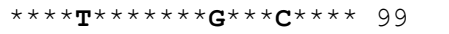 \\
\hline (03) & 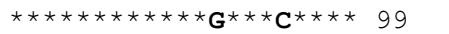 \\
\hline
\end{tabular}

\section{Manuscript to be reviewed}

\section{Gluconobacter oxydans}

621H (4) NC_006677.1

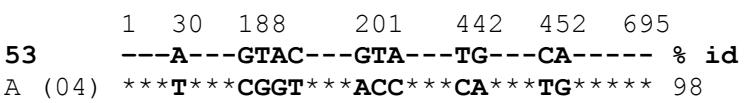

DSM 3504 (4)NZ_CP004373.1

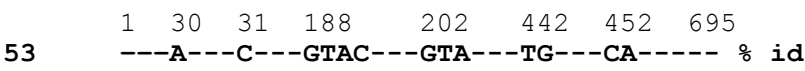

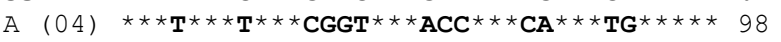

\section{d Staphylococcus epidermidis}

ATCC 12228 (5) NC_004461.1

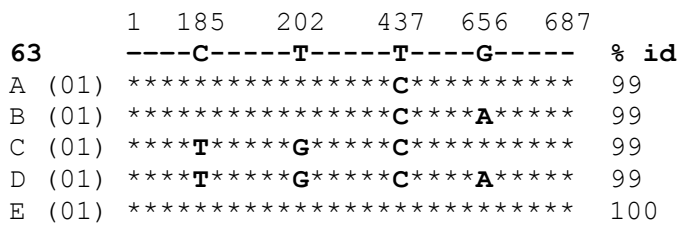

RP62A (6) NC_002976.3

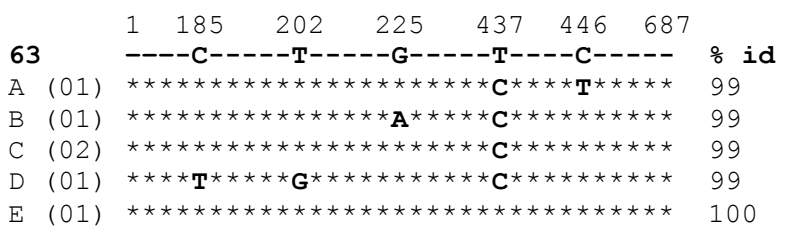

PM221 (6) NZ_HG813242.1

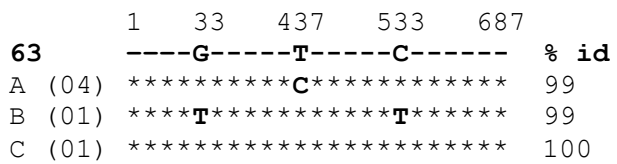

